Review Article

\title{
Role of the eNOS Uncoupling and the Nitric Oxide Metabolic Pathway in the Pathogenesis of Autoimmune Rheumatic Diseases
}

\author{
Anna Luczak, ${ }^{1}$ Marta Madej, ${ }^{1}$ Agata Kasprzyk, ${ }^{1}$ and Adrian Doroszko $\mathbb{D}^{2}$ \\ ${ }^{1}$ Department of Rheumatology, Wroclaw Medical University, Poland \\ ${ }^{2}$ Department of Internal Medicine, Hypertension and Clinical Oncology, Wroclaw Medical University, Poland \\ Correspondence should be addressed to Adrian Doroszko; adrian.doroszko@umed.wroc.pl
}

Received 20 February 2020; Accepted 31 March 2020; Published 13 April 2020

Guest Editor: Agata Stanek

Copyright (c) 2020 Anna Łuczak et al. This is an open access article distributed under the Creative Commons Attribution License, which permits unrestricted use, distribution, and reproduction in any medium, provided the original work is properly cited.

\begin{abstract}
Atherosclerosis and its clinical complications constitute the major healthcare problems of the world population. Due to the central role of endothelium throughout the atherosclerotic disease process, endothelial dysfunction is regarded as a common mechanism for various cardiovascular (CV) disorders. It is well established that patients with rheumatic autoimmune diseases are characterized by significantly increased prevalence of cardiovascular morbidity and mortality compared with the general population. The current European guidelines on cardiovascular disease (CVD) prevention in clinical practice recommend to use a 1,5-factor multiplier for $\mathrm{CV}$ risk in rheumatoid arthritis as well as in other autoimmune inflammatory diseases. However, mechanisms of accelerated atherosclerosis in these diseases, especially in the absence of traditional risk factors, still remain unclear. Oxidative stress plays the major role in the endothelial dysfunction and recently is strongly attributed to endothelial NO synthase dysfunction (eNOS uncoupling). Converted to a superoxide-producing enzyme, uncoupled eNOS not only leads to reduction of the nitric oxide (NO) generation but also potentiates the preexisting oxidative stress, which contributes significantly to atherogenesis. However, to date, there are no systemic analyses on the role of eNOS uncoupling in the excess CV mortality linked with autoimmune rheumatic diseases. The current review paper addresses this issue.
\end{abstract}

\section{Introduction}

Atherosclerosis and its clinical complications constitute the major healthcare problems of the world population [1-3]. Over the last decades, it has become clear that the vascular endothelium plays the central role throughout the atherosclerotic disease process, and all alterations initiating the onset and promoting the progression of the disease depend on the dynamic changes in endothelial cell phenotype. Endothelial dysfunction (ED), the early feature of atherosclerosis, precedes the development of morphologic changes and is the earliest detectable impairment of vascular function $[4,5]$. It is a consequence of chronic exposure to cardiovascular (CV) risk factors, and its progression is related to the intensity and duration of these factors $[6,7]$. Therefore, ED is regarded as a common mechanism for various $\mathrm{CV}$ disorders, and numerous clinical studies have shown that endothelial dysfunction can be an independent predictor of future cardio- vascular disease (CVD) progression and acute thrombotic events [8-11].

Patients with autoimmune rheumatic diseases even in the absence of CV risk factors have an almost twofold increase in $\mathrm{CV}$ morbidity and mortality than the general population. It is thought that persistent systemic inflammation enhances CV risk through direct or indirect mechanisms leading to accentuation of existing risk pathways [12]. Such evidence has now been implemented in European guidelines (ESC 2016 and 2019, EULAR 2010 with 2015/2016 update) and risk scores [13-16]. Increased production of proinflammatory mediators and cytokines results in enhanced oxidative stress, the hallmark of both autoimmune diseases and atherosclerosis [17-20]. Elevated ROS generation, via activation of the transcription factor, nuclear factor kappa-light-chain-enhancer of activated B cell (NF- $\kappa \mathrm{B}$ ) pathway, induces expression of inflammatory and immune genes (cytokines, chemokines, adhesion molecules, acute phase proteins, regulators of 


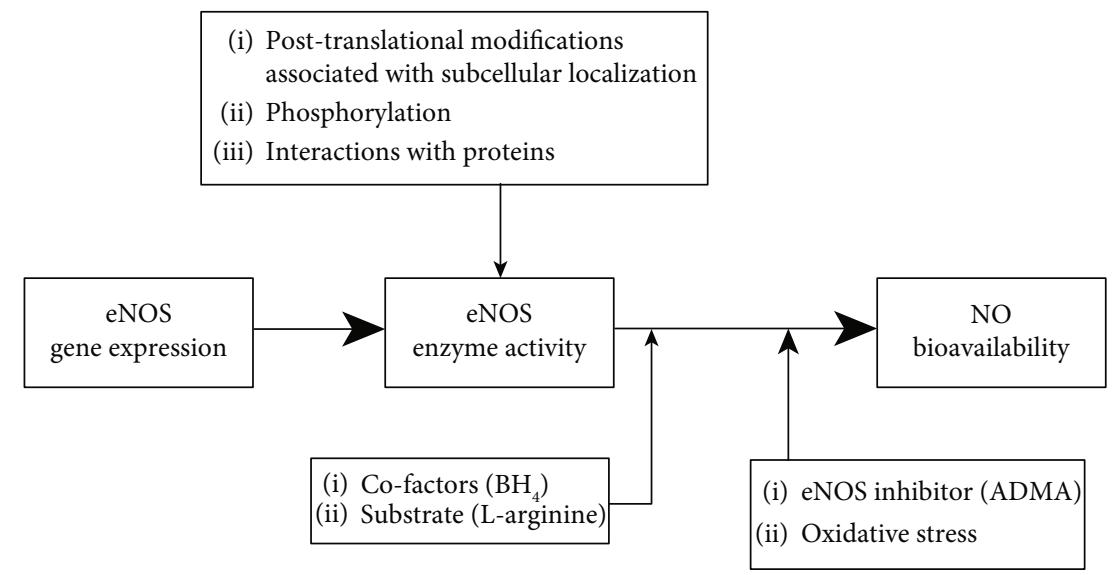

FIGURE 1: Balance between production and degradation of nitric oxide (NO) by oxidative stress determines endothelial NO bioavailability. Synthesis of NO can be regulated at the endothelial nitric oxide synthase (eNOS) gene expression level and eNOS enzymatic activity level. The eNOS activity depends also on substrate and cofactor availability and the presence of oxidative stress and endogenous inhibitor asymmetric dimethylarginine (ADMA). Adapted from Yang and Ming [177]. Abbreviations: eNOS: endothelial nitric oxide synthase; NO: nitric oxide; $\mathrm{BH}_{4}$ : tetrahydrobiopterin; $\mathrm{ADMA}$ : assymetric dimethylarginine.

apoptosis, and cell proliferation). These mediators on one hand promote change in endothelial phenotype, known as endothelial activation; on the other hand, they potentiate inflammation via further recruitment of adaptive and innate immune cells and ROS generation, leading to persistence of inflammation and disease progression $[21,22]$. It is thought that the destructive loop of oxidative stress and inflammation leads to development of endothelial dysfunction, a fundamental feature of atherosclerosis [23].

Due to the fact that atherosclerosis is a complex disease, no single mechanism can fully explain the endothelial dysfunction. However, decreased nitric oxide (NO) bioavailabilitywithsubsequentinabilityofendothelium toinitiate vasodilatation and exhibit multiple antiatherogenic functions appears to play a major role [24]. Decreased NO bioavailability may result from its limited production and/or increased NO degradation by reactive oxygen species (ROS) (Figure1).ReducedNOgenerationcanbeduetodecreasedendothelial NO synthase (eNOS) expression and/or activity, eNOS uncoupling, impaired NO-mediated signaling events, and oxidative stress. Among these mechanisms, the eNOS uncoupling has recently attracted the gaining attentions. However, there is scarcely no data in the literature on the role of the eNOS uncoupling in atherogenesis in autoimmune rheumatic diseases. The currentreview paperaddressesthisgapinliterature.

\section{Molecular Mechanisms of the eNOS Uncoupling: Pathophysiological Considerations and Potential Therapeutic Implications}

2.1. eNOS Uncoupling (Figure 2): General Information. A number of studies have revealed that under pathological conditions, due to the enhanced oxidative stress, the eNOS may become dysfunctional resulting in production of superoxide instead of NO. Moreover, the expression of eNOS is increased by ROS through posttranscriptional and posttrans- lational modifications, although the NO bioavailability is reduced. This phenomenon contributes significantly to endothelial dysfunction and cardiovascular disease not only by reducing the NO generation but also by triggering the preexisting oxidative stress $[25,26]$.

Produced by the uncoupled eNOS, superoxide scavenges NO leading to the peroxynitrite formation. Both ROS exert multiple proatherogenic effects, including effects on eNOS function. Peroxynitrite oxidizes tetrahydrobiopterin $\left(\mathrm{BH}_{4}\right)$, the eNOS cofactor to the trihydrobiopterin $\left(\mathrm{BH}_{3}\right)$ radical, resulting in the eNOS uncoupling, perpetual superoxide production, and subsequent peroxynitrite formation [27]. It also reduces endothelial transport of L-arginine, the exclusive substrate for eNOS, and increases the rate of L-arginine efflux [28]. Peroxynitrite directly oxidizes the reduced glutathione (GSH), its endogenous scavenger, which plays a major role in the cellular defense against reactive oxygen species. Similarly, via nitration of superoxide dismutase (SOD), peroxynitrite inactivates the enzyme, leading to diminished antioxidant cellular defense mechanisms and increase in superoxide levels $[29,30]$. Elevated superoxide levels are also the result of peroxynitrite action-induced protein phosphatase 2A (PP2A) activation, which leads in turn to the dephosphorylation of eNOS and therefore decrease in enzyme activity and subsequent NO generation [31,32]. Peroxynitrite and superoxide, the known contributors to endothelial dysfunction, have also multiple indirect effects on the eNOS function. Peroxynitrite inactivates prostacyclin synthase (PGIS), an enzyme that catalyzes the isomerization of prostaglandin $\mathrm{H}_{2}$ to prostacyclin, widely known for its vasoprotective activity, therefore resulting in formation of vasoconstricting prostaglandins including thromboxane $\mathrm{A}_{2}$. Recent studies have shown that stimulation of thromboxane receptor (TPr) by thromboxane $\mathrm{A}_{2}$ and prostaglandin $\mathrm{H}_{2}$ promotes ROS formation in vascular smooth muscle cells and endothelial cells by activating nicotinamide adenine dinucleotide phosphate $(\mathrm{NADPH})$ oxidase facilitating eNOS deactivation through increased oxidative stress $[33,34]$. Both superoxide and 


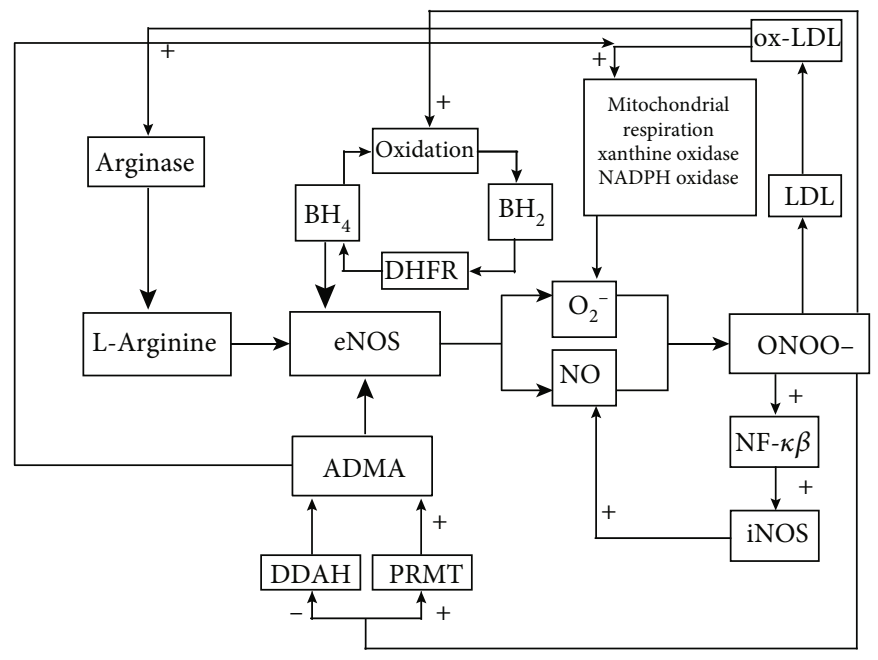

FIgURE 2: Mechanisms of endothelial nitric oxide synthase (eNOS) uncoupling in endothelial dysfunction. A depletion of eNOS cofactor tetrahydrobiopterin $\left(\mathrm{BH}_{4}\right)$, an L-arginine deficiency, and an increase in endogenous eNOS inhibitor, asymmetric dimethylarginine (ADMA), leads to eNOS uncoupling. Produced by the uncoupled enzyme, superoxide scavenges nitric oxide (NO) leading to the peroxynitrite formation. Peroxynitrite (1) oxidizes $\mathrm{BH}_{4}$, resulting in the eNOS uncoupling and perpetual superoxide production and subsequent peroxynitrite formation; (2) oxidizes low-density lipoproteins (LDL) forming oxidized LDL (ox-LDL) which in turn through the scavenger receptor, lectin-like oxidized low-density lipoprotein receptor-1 (LOX-1), downregulate the enzyme expression. Furthermore, ox-LDL stimulate nicotinamide adenine dinucleotide phosphate oxidase (NADPH oxidase) and xanthine oxidase to produce reactive oxygen species (ROS) in excess and increase arginase activity leading to reduction in L-arginine availability for nitric oxide synthase (NOS) and subsequent eNOS uncoupling and impaired NO generation. Moreover, arginase via increased formation of polyamines and L-proline stimulates vascular smooth muscle cell proliferation and extracellular matrix deposition, thereby contributing to intimal hyperplasia and remodeling processes; (3) nitrosylates the cationic amino acid transporter, therefore inhibiting the L-arginine transport in endothelial cells and increasing the rate of arginine efflux; (4) increases the activity of protein-arginine methyl transferase (PRMTs) and inhibits that of dimethylarginine dimethylaminohydrolase (DDAH), resulting in elevated ADMA levels, which in turn via inhibition of NO synthesis and eNOS uncoupling enhance production of ROS. Oxidative stress in turn upregulates ADMA levels; (5) through activation of transcription factor, nuclear factor kappa-light-chain-enhancer of activated B cells (NF- $\kappa \mathrm{B})$ induces expression of inducible nitric oxide synthase (iNOS), arginase, and inflammatory and immune genes (cytokines, chemokines, adhesion molecules, acute phase proteins, regulators of apoptosis, and cell proliferation) potentiating inflammation via further recruitment of adaptive and innate immune cells and ROS generation, leading to persistence of inflammation and disease progression. Abbreviations: eNOS: endothelial nitric oxide synthase; $\mathrm{NO}$ : nitric oxide; $\mathrm{BH}_{4}$ : tetrahydrobiopterin; $\mathrm{ADMA}$ : asymmetric dimethylarginine; $\mathrm{O}_{2}^{-}$: superoxide; $\mathrm{ONOO}$-: peroxynitrite; $\mathrm{BH}_{2}$ : dihydrobiopterin; DHFR: dihydrofolate reductase; ox-LDL: oxidized LDL; NADPH oxidase: nicotinamide adenine dinucleotide phosphate oxidase; LDL: low-density lipoproteins; iNOS: inducible nitric oxide synthase; NF- $\kappa$ B: nuclear factor kappa light-chainenhancer of activated B cells; DDAH: dimethylarginine dimethylaminohydrolase; PRMT: protein arginine methyl transferase.

peroxynitrite also oxidize low-density lipoproteins (LDL) forming oxidized LDL (ox-LDL), which in turn through the scavenger receptor, lectin-like oxidized low-density lipoprotein receptor-1 (LOX-1), downregulates the enzyme expression. Furthermore, ox-LDL stimulate NADPH oxidase and xanthine oxidase to produce ROS in excess, promoting a vicious cycle mechanism of oxidative stress and vascular damage $[35,36]$.

Numerous mechanisms have been proposed to play a role in the eNOS uncoupling in atherosclerosis: depletion of eNOS cofactor $\mathrm{BH}_{4}$, L-arginine deficiency, and increase in endogenous eNOS inhibitor, asymmetric dimethylarginine (ADMA) [37]. All these mechanisms are discussed below.

2.2. Asymmetric Dimethylarginine (ADMA). ADMA is a naturally occurring amino acid formed from the proteolysis of methylated arginine residues in intracellular proteins that are posttranslationally modified by a class of enzymes known as protein-arginine methyl transferases (PRMTs). Following proteolysis, free methylarginines are released and subsequently converted to citrulline and dimethylamine by dimethylarginine dimethylaminohydrolase (DDAH). ADMA is a key NOS inhibitor-it competes with L-arginine for the binding site in the active center of NOS isoforms, thereby resulting in decreased NO generation [38-40]. Increased ADMA reduces NO bioavailability leading to subsequent inflammation and oxidative stress, the typical features of endothelial dysfunction, contributing substantially to cardiovascular risk [41, 42]. Therefore, increased ADMA levels have been associated with several risk factors and cardiovascular morbidity and mortality. Indeed, numerous studies have confirmed its role as an established independent predictor for cardiovascular events and all-cause cardiovascular mortality [43-45]. In animal models, ADMA levels correlated with vascular function and the degree of atherosclerosis, in humans with cholesterol levels [46, 47]. Elevated ADMA levels are largely due to increased PRMT activity or decreased DDAH activity. The regulation of gene expression and activity of PRMT and DDAH remains predominantly unclear. However, activities of both enzymes are redox sensitive. Oxidative stress has been shown to increase the activity of PRMTs and inhibit that of DDAH, resulting in elevated ADMA levels, which in 
turn via inhibition of NO synthesis and eNOS uncoupling enhance production of ROS [48]. Therefore, ADMA promotes superoxide production by eNOS, and the resulting oxidative stress upregulates ADMA levels [49]. Tumor necrosis factor-alpha (TNF- $\alpha$ ) and high levels of glucose and homocysteine diminish DDAH activity via induction of oxidative stress. Similarly does oxidized low-density lipoprotein (ox-LDL) [50-52]. Increased ADMA in turn upregulates the LOX-1 expression, the main receptor for ox-LDL in endothelial cells, resulting in enhanced production of oxidized LDL and intracellular generation of reactive oxygen species, creating a vicious cycle mechanism $[53,54]$.

Negative regulation of $\mathrm{NO}$ synthesis can also be mediated through overproduction of methylated arginine analogues such as ADMA. Recently, many clinical studies have demonstrated that plasma levels of ADMA were elevated in RA patients regardless of the presence of cardiovascular disease [55-67]. Furthermore, ADMA has been reported to be related to indices of endothelial dysfunction or subclinical atherosclerosis in some $[56,65,68]$, but not all, conducted studies $[58,60,61,67,68]$. In patients with high disease activity and no overt atherosclerotic disease or classic risk factors, high plasma ADMA levels significantly correlated with IMT [67], coronary flow reserve (CFR) [56], and pulse wave velocity (PWV) [58], whereas in those with evident atherosclerosis and $\mathrm{CV}$ risk factors, negative correlation between ADMA and FMD [65] and carotid IMT (cIMT) $[62,68]$ was found. In the latter subgroup of patients also, a positive relation was observed between the ADMA:SDMA ratio (suggested as the index of dimethylarginine dimethylaminohydrolase activity) and microvascular endothelial function [68] and arterial stiffness [62]. However, these relationships were not observed in RA patients with low and moderate disease activities-although structural and functional changes in vessels and heart were detected by means of multiple noninvasive, validated methods including cIMT, FMD, CFR, PWV, laser Doppler, and subendocardial viability ratio (SEVR), no associations between dimethylarginines and assessments of vascular morphology and function were found [56, 61, 65]. As an explanation of these findings, it has been suggested that inflammatory mechanisms responsible for synovial lesions might also occur in the vascular wall and promote the development of advanced atherosclerosis. Oxidative stress induced by proinflammatory cytokines has been shown to increase the activity of PRMTs and inhibit that of DDAH, resulting in elevated ADMA levels. The latter can be also due to increased endothelial cell turnover with potential liberation of ADMA during cell catabolism. Increased ADMA in turn contributes directly to oxidative stress by causing endothelial NOS uncoupling and switching it to a superoxide synthase. ADMA also significantly increases TNF- $\alpha$ levels in human endothelial cells and thus participates in the pathogenesis of vascular injury in RA $[56,62$, $66,67,69]$. Hence, these data indicate close interactions between endothelial injury and systemic inflammation.

2.3. Tetrahydrobiopterin $\left(\mathrm{BH}_{4}\right) \cdot \mathrm{BH}_{4}$ is a critical cofactor for all the NOS isoforms and a regulator of their function [37]. It has been shown that NO generation and eNOS correlate closely with the intracellular concentration of $\mathrm{BH}_{4}$ [70]. It is synthesized de novo from guanosine triphosphate (GTP) in a multistep pathway that involves GTP cyclohydrolase I (GTPCH I), 6-pyruvoyltetrahydropterin synthase, and sepiapterin reductase, respectively. GTPCH I is a ratelimiting enzyme for $\mathrm{BH}_{4}$ biosynthesis and therefore plays a major role in controlling the NOS function [71, 72]. Many lines of evidence indicate that oxidative degeneration of $\mathrm{BH}_{4}$ by ROS leads to the eNOS uncoupling, reduction in NO bioavailability, and increased reactive oxygen species production $[73,74]$. Indeed, oxidation of $\mathrm{BH}_{4}$ forms dihydrobiopterin $\left(\mathrm{BH}_{2}\right)$ and biopterin. $\mathrm{BH}_{2}$ binds with fairly high affinity to eNOS without supporting its catalytic activity [75]. The uncoupled enzyme generates superoxide rather than $\mathrm{NO}$ leading to further limitation of $\mathrm{BH}_{4}$ availability. However, $\mathrm{BH}_{2}$ can be recycled to $\mathrm{BH}_{4}$ by dihydrofolate reductase (DHFR), which regulates the rate of $\mathrm{BH}_{4}$ regeneration [76]. Therefore, $\mathrm{BH}_{4}$ bioavailability is determined by enzymatic de novo synthesis, recycling, and oxidative degradation. There is little information on regulatory mechanisms of GTPCH and DHFR gene expression or activity. BH4 and high concentrations of $\mathrm{BH}_{2}$ inhibit GTPCH-1 and subsequently de novo synthesis of $\mathrm{BH}_{4}$, while insulin and mediators such as interferon gamma (IFN- $\gamma$ ), TNF- $\alpha$, and interleukin- 1 beta (IL-1 $\beta$ ) can upregulate its activity and expression [77-80]. Expression of DHFR can be downregulated by angiotensin II [81]. It is thought that among these two enzymes, DHFR is critical to eNOS function, especially in cells that do not contain the apparatus required for efficient synthesis of $\mathrm{BH}_{4}$ or under conditions of low total biopterin levels, as recycling it can reduce eNOS-dependent oxidation of $\mathrm{BH}_{4}$ that would further decrease $\mathrm{BH}_{4}$ levels and enhance eNOS uncoupling [82]. In endothelial dysfunction and many models of cardiovascular disease, the $\mathrm{BH}_{4}$ levels have been found decreased. Therefore, recent studies have shown that pharmacological supplementation of $\mathrm{BH}_{4}$ improves vascular function in patients with diabetes, essential hypertension, and hypercholesterolemia and in chronic smokers [83-95].

Recently, it has been demonstrated that deficiency of $\mathrm{BH}_{4}$ may contribute in part to formation of the uncoupled eNOS. Indeed, a decrease in serum levels of $\mathrm{BH}_{4}$ in AIA rats compared to the control group was reported, and administration of $\mathrm{BH}_{4}$ restored endothelial function. Therefore, the authors suggested that eNOS contributes to amplification of oxidative stress in vasculature, and this contribution is mediated by the loss of $\mathrm{BH}_{4}$ availability $[96,97]$. Beneficial effects of oral $\mathrm{BH}_{4}$ supplementation were then investigated in humans. Therapy with $\mathrm{BH}_{4}$ in patients with active $\mathrm{RA}$ improved endothelial function as assessed by vasodilatory response to reactive hyperemia. A decrease in $\mathrm{BH}_{4}$ levels in RA patients was attributed by the authors to increased expression and activation of inducible nitric oxide synthase (iNOS) in endothelial cells during chronic inflammation, which leads to eNOS uncoupling via limiting $\mathrm{BH}_{4}$ availability for eNOS. Also, ROS generated by myeloperoxidase released from activated neutrophils contribute to decreased $\mathrm{BH}_{4}$ levels via their oxidation to inactive $\mathrm{BH}_{2}[98,99]$. In an animal model of arthritis, serum $\mathrm{BH}_{4}$ levels besides supplementation can be increased upon administration of fluvastatin [97]. It has been 
reported in the general population that statins upregulate eNOS expression by stabilizing its mRNA and induce phosphorylation and activation of eNOS via the protein kinase Akt pathway. The authors showed that fluvastatin decreased expression of p22phox mRNA, a membrane-associated component of NADPH oxidase, resulting in inhibition of enzyme activity and decreased ROS generation. Therefore, they indicated that increase in $\mathrm{BH}_{4}$ availability due to decreased ROS production achieved with fluvastatin therapy prevents eNOS uncoupling $[97,100]$. A similar mechanism of action presents etanercept, a TNF inhibitor [101].

Interestingly, methotrexate (MTX) inhibits NF- $\kappa \mathrm{B}$ activation through blockade of $\mathrm{BH}_{4}$ synthesis. It inhibits tetrahydrofolate reductase which recycles $\mathrm{BH}_{2}$ to $\mathrm{BH}_{4}$, leading to eNOS uncoupling and ROS production. In turn, increased ROS generation activates the Jun- $\mathrm{N}$-terminal kinase (JNK) and JNK-dependent induction of tumor protein p53 (p53) and cyclin-dependent kinase inhibitor 1 (p21) resulting in decreased NF- $\kappa$ B activation. Therefore, MTX may contribute to reduced $\mathrm{BH}_{4}$ bioavailability in the endothelium. However, the study investigating the impact of $\mathrm{BH}_{4}$ supplementation on endothelial function found no difference between patients on MTX and those not receiving MTX. Furthermore, patients treated with MTX had a greater increase in flowmediated dilatation (FMD) following $\mathrm{BH}_{4}$ administration probably due to reduced levels of inflammation. Although the study was not powered to look at this difference, it has been reported recently that in activated $\mathrm{T}$ cells, inhibition of $\mathrm{BH}_{4}$ synthesis decreases production of the proinflammatory IFN- $\gamma$ and increases production of the antiinflammatory IL-4. MTX induces a similar shift and therefore downregulates expression of proinflammatory cytokines IL-1, IL-2, IL-6, and IFN- $\gamma$ and upregulates expression of antiinflammatory cytokines such as IL-4 and IL-10 in RA patients $[98,102,103]$.

2.4. L-Arginine Deficiency. A semiessential amino acid L-arginine is the exclusive substrate for nitric oxide synthase, and its availability is one of the rate-limiting factors in cellular NO production [37]. Since reduction in L-arginine availability has emerged as an important mechanism underlying decreased NO bioavailability and endothelial dysfunction, many clinical and experimental studies during the past decade have shown beneficial effects of L-arginine supplementation in both animal studies and humans [104-112]. However, most recent studies are inconsistent with these findings showing no sustained effect or no effect of L-arginine administration on endothelial function [113-119]. This could be due to the complex biochemical metabolism of L-arginine [120]. L-Arginine is derived from dietary intake, protein breakdown, or endogenous de novo synthesis from L-citrulline catalyzed by the enzymes argininesuccinate synthase (ASS) and arginine-succinate lyase (ASL) [121]. Afterwards, it is converted into ornithine and urea by arginase, agmatine by L-arginine decarboxylase (ADC), and NO by NOS. Therefore, arginine metabolism and availability depend on the level of its dietary intake and endogenous synthesis on the one hand and the extent of catabolism on the other hand [122]. Whereas diminished bioavailability of NO is a common mechanism of various vascular disorders and endothelial dysfunction, the deficiency of L-arginine available for eNOS has been recently related to enhanced arginase activity [123]. The latter notion has been supported by findings in atherosclerosis and other cardiovascular disorders where arginase expression or activity has been found increased, suggesting that it plays a predominant role in these conditions [124-127]. However, information on exact regulatory mechanisms of arginase gene expression or activity is still missing. Its expression can be upregulated by proinflammatory factors: TNF- $\alpha$ and interferon- $\gamma$, ROS, oxidized LDL via the LOX-1 receptor, hyperglycaemia, thrombin, hypoxia, and angiotensin II. Arginase, both isoforms I and II, is expressed in endothelial and smooth muscle cells of the vascular wall and competes with NOS for the substrate L-arginine [128]. Increased activity of arginase leads to reduction in L-arginine availability for NOS, thereby decreasing the production of $\mathrm{NO}$ and resulting in eNOS uncoupling. Uncoupled enzyme produces superoxide instead of NO which further increases arginase activity and impair NO generation via oxidation of tetrahydrobiopterin [129-132]. Arginase also inhibits the L-arginine transport in endothelial cells further exacerbating L-arginine deficiency and downregulating NO production [133]. Moreover, arginase, by increased formation of polyamines and L-proline, stimulates vascular smooth muscle cell proliferation and extracellular matrix deposition, thereby contributing to intimal hyperplasia and remodeling processes. Similarly, promoting abnormal remodeling and neointimal hyperplasia reduced NO bioavailability [134, 135].

eNOS uncoupling resulting in reduced NO bioavailability and increased oxidative stress causes and aggravates dysregulation of endothelial function. New therapeutic strategies for atherosclerosis are aimed at preventing or reversing the endothelial dysfunction, before clinical manifestations and disease progression will occur. For better understanding of pathophysiology of endothelial dysfunction, novel pharmacological approaches focused on eNOS recoupling are being investigated. Several drugs currently in clinical use, inhibitors of the renin-angiotensin-aldosterone system, statins, and nebivolol, show many pleiotropic actions. Recently, it has been demonstrated that they may prevent or reverse the eNOS uncoupling and improve endothelial function and NO bioavailability in animal models. Similarly do resveratrol, sepiapterin, folic acid, AVE3085, and AVE9488 (enhancers of endothelial nitric oxide synthase acting on the eNOS gene transcription). All these compounds target eNOS through multiple direct and indirect mechanisms; however, the detailed mechanisms of their action are beyond the scope of this review and are comprehensively reviewed elsewhere $[25,37,136]$. Despite beneficial effects in animal models, applying these experimental results to clinical treatment still requires further studies and more extensive investigation.

Emerging evidence has suggested the deficiency of L-arginine available for eNOS as an etiology for endothelial dysfunction and has related it to enhanced arginase activity [137]. In an animal model of arthritis (adjuvant-induced arthritis), it has been shown that arginase II isoform expression and activity were significantly increased and correlated 
with disease activity $[138,139]$. Nevertheless, high plasma arginase levels failed to correlate with plasma levels of IL-6. Although it is clearly recognized that systemic inflammation with increased proinflammatory cytokine production induces arginase expression, the exact regulatory mechanisms of enzyme activity or gene expression in the endothelial cells still remain elusive. In contrast, eNOS activity was found decreased with no change in its expression, and the authors attributed this discrepancy between eNOS activity and expression to decreased availability of the substrate for the enzyme. Moreover, they indicated that limiting L-arginine accessibility for NOS arginase upregulation contributes to enzyme uncoupling and endothelial dysfunction. Indeed, impaired endothelial function assessed by the vasodilating response to acetylcholine (Ach) was found in AIA rats, and arginase inhibition with a selective inhibitor $\mathrm{N}_{\mathrm{w}}$-hydroxynor-L-arginine (nor-NOHA) restored vascular function. The effect of a curative treatment with nor-NOHA on vascular function of AIA rats was further investigated, and authors indicated that it is mediated by an increase in NOS activity and endothelium-derived hyperpolarizing factor (EDHF) production; a decrease in cyclooxygenase 2 (COX-2), thromboxane (TX), and prostaglandin $\mathrm{I} 2\left(\mathrm{PGI}_{2}\right)$ synthase and NADPH oxidase activities; and a decrease in superoxide production and secreted vascular endothelial growth factor (VEGF) levels. Both enhanced NOS activity and reduced superoxide production can be due to the decrease in vascular eNOS uncoupling, thanks to the beneficial effect of arginase inhibition and restored L-arginine bioavailability. Interestingly, arginase inhibition had no impact on disease severity assessed by clinical, histological, and radiological parameters, whereas it fully reversed endothelial dysfunction in AIA rats. Furthermore, plasma IL-6 levels did not correlate with endothelial dysfunction. Taking these findings into account, the authors conclude that endothelial dysfunction is not the consequence of the disease, at least in the chronic phase of the AIA model. Since the reduction of endothelial dysfunction seems to be possibly independent of RA disease activity, they indicated that the benefits provided by nor-NOHA are related to the direct modulation of endothelium-derived vasorelaxant pathways rather than an anti-inflammatory effect $[138,139]$. It is noteworthy that this beneficial effect of arginase activity inhibition can also be obtained with statins, diclofenac, and etanercept [101, 140, 141].

\section{Clinical Implications: eNOS Uncoupling and Autoimmune Rheumatic Disease}

It is well established that patients with rheumatic autoimmune diseases are characterized by significantly increased prevalence of cardiovascular morbidity and mortality than the general population. The current European guidelines on cardiovascular disease (CVD) prevention in the clinical practice recommend to use a 1,5-factor multiplier for $\mathrm{CV}$ risk in rheumatoid arthritis as well as in other autoimmune inflammatory diseases. However, mechanisms of accelerated atherosclerosis in these diseases, especially in the absence of traditional risk factors, still remain unclear.
3.1. Systemic Lupus Erythematosus (SLE). It is now clearly recognized that SLE patients are at high risk of developing CVD, and this excessive risk is especially pronounced in premenopausal women. Traditional risk factors do not fully account for this association, and the disease itself is considered an independent CV risk factor [142]. Therefore, precocious atherosclerosis is likely attributable to the consequences of inflammation, which is in line with observations that disease duration, higher damage index score, and less aggressive immunosuppression are associated with increased CVD burden in SLE patients. Till now, there are no biomarkers that predict CV events in SLE patients, and the known ones used to assess CV risk in the general population have limited or no value in SLE [143-145]. However, patients with SLE show enhanced endothelial dysfunction, which is regarded as a common mechanism for various $\mathrm{CV}$ disorders and considered the first step in atherosclerosis. Underlying mechanisms and its pathogenesis in SLE are still poorly understood [146, 147]. It is thought that the common denominator for multiple mechanisms contributing to the development of endothelial dysfunction is diminished activity of endothelial nitric oxide synthase and loss of nitric oxide production. Recent analyses have shown that SLE-specific circulatory factors, TNF- $\alpha$, interleukin-17, interferons, ligand of cluster of differentiation 40 (CD40L), and C-reactive protein (CRP), lead to endothelial dysfunction via promotion of abnormal eNOS function and enhanced oxidative stress [148]. Among these mediators, type I interferons gained considerable attention. Continuous inflammatory production of interferon-alpha (IFN- $\alpha$ ) and subsequent increased expression of IFN- $\alpha$-regulated genes, referred as IFN signature, due to activation of plasmacytoid dendritic cells by immune complexes, consisting of autoantibodies in combination with deoxyribonucleic acid- (DNA-) or ribonucleic acid- (RNA-) containing autoantigens, have been reported in SLE patients. Studies on animals and humans have provided evidence that IFN accelerate atherosclerosis on multiple stages [149-151]. To date, no studies were conducted to determine direct effects of IFN on eNOS function and NO generation. However, IFN type I has been reported to have impact on enzyme cofactors, its specific transcription factors, and oxidative stress pathways [151]. Animal and human studies indicate that IFN- $\alpha$ leads to depletion of $\mathrm{BH}_{4}$ via oxidation, serving as a potential mediator of eNOS uncoupling and oxidative stress $[152,153]$. There are also scarce studies investigating the role of interferon on L-arginine availability. However, a study conducted in patients with high-risk melanoma showed that therapy with pegylated IFN- $\alpha$ results in a marked decrease in the synthesis of NO and arginine availability $[154,155]$. Information on impact on arginase activity is also missing. However, recently, a significant increase in serum arginase 1 activity was detected in the SLE patients. Its levels were positively correlated with the disease severity and IL-17. Furthermore, arginase 1 was found to enhance $\mathrm{T}$ helper 17 (Th17) cell differentiation both in vitro and in vivo, augmenting inflammation [156]. Although direct effect of these observations on eNOS function warrants further research, it is thought that inflammatory and immune process characteristics for SLE contribute to the development 
of premature atherosclerosis [157]. As reported, disease marker anti-Smith (anti-Sm) and anti-ribonucleoprotein (anti-RNP) antibodies stimulate IFN type I production by plasmacytoid dendritic cells [158]. Surprisingly, an inverse correlation between the presence of atherosclerosis in SLE (evaluated as arterial stiffness and presence of carotid plaque) and anti-nuclear antibodies was observed. Actually, patients with plaque had less frequent anti-Sm and/or anti-RNP antibodies than those without plaque [159]. Therefore, further studies are needed to clarify why patients with anti-nuclear antibodies have less pronounced subclinical atherosclerosis, even having more systemic and severe course of disease, interspersed with episodes of acute disease flares.

Besides IFN, anti-DNA autoantibodies are the hallmark of SLE. It has been implicated that anti-double-stranded DNA (anti-dsDNA) antibodies may have a role in the development of cardiovascular disease in SLE by enhancing ADMA production and by potentiating the inflammatory reaction. Indeed, it has been demonstrated in vitro that in the presence of anti-dsDNA, methylation of arginine residues in proteins by PRMT I is increased; therefore, antidsDNA antibodies may be a trigger for enhanced ADMA production in SLE [160]. Results of in vitro studies were confirmed by findings observed in vivo, where there are high plasma levels of complement (C3 and C4), measures of disease activity and organ damage, $\mathrm{CV}$ events, and prednisone use $[161,162]$. Although ADMA is significantly associated with risk factors for CVD in the general population, no such correlation was found in SLE patients [161, 162].

Subclinical atherosclerosis in SLE has been reported and described by different methods. In SLE patients without CVD, the ADMA was independently associated with the coronary calcium score and arterial stiffness [159, 162]. Nevertheless, no association with the presence or extent of carotid atherosclerosis (assessed by carotid ultrasonography-intima-media thickness (IMT) and plaque) was found $[159,162]$. These inconsistent findings are attributed by authors to differential effect of ADMA on distinct vascular beds. There are two major mechanisms proposed underlying vascular disease in SLE: IFN-induced reduction of endothelial cell proliferation and survival with subsequent impaired repair and remodeling and ADMA-induced inhibition of eNOS [159]. Nevertheless, further studies are needed to investigate the role of the NO pathway and its components in atherogenesis in SLE.

3.2. Rheumatoid Arthritis (RA). Similar to SLE, endothelial dysfunction has been reported in RA patients, even in the very early stages of disease [163]. Since it has been speculated that RA-related inflammation might contribute to endothelial dysfunction, anti-TNF therapy has been shown to improve vascular function, which strongly indicates involvement of systemic inflammation in the development of premature atherosclerosis [164]. Recent studies on animals showed that endothelial function in adjuvant-induced arthritis (AIA) rats is significantly depressed without any histologic damage, supporting the idea that endothelial dysfunction occur before overt vascular damage [96]. The mechanism of endothelial dysfunction in RA remains still incompletely understood, but decreased NO bioavailability along with increased ROS production has been suggested. Besides NADPH oxidase, uncoupling eNOS has been identified as an important source of ROS and its expression was significantly increased at both messenger RNA (mRNA) and protein levels in AIA rats. Furthermore, incubation of homogenates of AIA rat aortas with L-arginine led to overproduction of superoxide.

Although RA disease-related inflammation may contribute to elevated ADMA levels and increased CVD risk in RA, the association between ADMA and disease activity has been an issue of debate, as previous studies are heterogenous in results. It has been demonstrated that baseline disease status (mainly elevated erythrocyte sedimentation rate (ESR) and also CRP) and cumulative inflammatory burden (6 years of follow-up) had a positive correlation with current ADMA levels as-according to authors-patients with longer periods of uncontrolled disease are more prone to develop endothelial dysfunction due to the higher cumulative inflammatory burden on the vasculature [165]. A few studies have reported a positive correlation between ADMA and inflammatory markers (CRP and ESR), disease activity (DAS 28) and duration, and clinical parameters of disease status (tender and swollen joints, morning rigid) independently of the presence of classical risk factors and CVD [61, 64-66, 165-168], not confirmed by other studies [60,61, 63, 66, 169]. Similar results were obtained concerning RA disease-specific markers-rheumatoid factor (RF) and anti-citrullinated protein antibodies (ACPA) $[60,61,63-66,168]$. Interestingly, no association was found with traditional risk factors $[55,68]$, apart from homeostatic model assessment (HOMA) referred to as the indicator of insulin resistance, being the only independent predictor of elevated ADMA levels in RA patients [169]. Additionally, ADMA has been shown to correlate with other biomarkers of vascular dysfunction such as endothelial progenitor cell (EPC) count [67].

The studies investigating a possible impact of the diseasemodifying antirheumatic drugs (DMARDs) on ADMA levels also provided conflicting results. In a small prospective study conducted on treatment-naïve patients with early RA, a significant decrease in ADMA serum levels after 12 months of immunosuppressive treatment with synthetic and biologic DMARDs along with glucocorticoids was reported [60]. However, no increase in carotid IMT was observed after 12 months of DMARD therapy. These findings were not confirmed by another study performed in a similar subgroup of patients treated for 18 months with either methotrexate or adalimumab [170]. Although an improvement in CFR was found, both carotid IMT and plasma ADMA levels did not show significant changes after therapy. The lack of effect of methotrexate and TNF inhibitors (etanercept, adalimumab, and infliximab) on plasma concentrations of ADMA was also demonstrated in long-standing RA patients [58, 61]. Data from studies determining the impact of short-term antiTNF administration are also inconsistent. One report described similar to baseline ADMA values after 2 weeks and 3 months of anti-TNF treatment with etanercept, infliximab, or adalimumab [167], whereas others demonstrated a significant reduction of dimethylarginine in the group of 
patients receiving etanercept or adalimumab $[166,171]$. In the latter study by Spinelli et al., besides a decrease in ADMA plasma concentrations, anti-TNF therapy restored circulating endothelial progenitor cell levels, although a not significant increase of FMD was observed. Finally, it has been shown that TNF inhibitors improved the L-arginine/ADMA ratio due to the increase in L-arginine, and the L-arginine/ADMA ratio was longitudinally related to PWV after initiation of antiTNF- $\alpha$ therapy [58]. Acute and chronic oral treatments with glucocorticoids have also different effects on arginine metabolites; while acute prednisolone therapy has no impact, chronic prednisolone treatment reduces ADMA and SDMA plasma concentrations [57].

Given the evident role of TNF in atherosclerosis and RA pathogenesis and its inhibitory effect on DDAH leading to ADMA accumulation, a beneficial effect of TNF inhibition has been postulated; however, results of conducted studies did not demonstrate a consistent decrease in ADMA levels with subsequent improvement in vascular morphology and function suggesting that the ADMA level does not seem to be a straightforward indicator of endothelial dysfunction and subclinical atherosclerosis in rheumatic diseases. Due to the complexity of the processes observed in RA and atherosclerosis, contributions of traditional and disease-related risk factors cannot be excluded as well as other mechanisms of DMARD action compared with increased NOS activity/expression. The heterogeneity of the study population and methods used to assess subclinical atherosclerosis may also account for the lack of concordance of the results and limit the usefulness of ADMA as a marker for atherosclerotic risk stratification $[61,165,171]$.

In accordance with results from animal studies, an increase in plasma arginase activity with a significant decrease in arginine bioavailability was reported in patients with RA [55]. Similar observations were made regarding the catabolic product of arginase (L-ornithine) and catabolic product of NOS (L-citrulline). Interestingly, it has been shown that elevated arginase activity was associated with prior history of CVD in a subgroup of patients with RA, but it did not show any correlation with traditional risk factors. In contrast to animal studies, significant increase in arginase activity seemed to be independent of disease activity; however, patients in the analyzed cohort had relatively low RA disease activity reflected by Disease Activity Score (DAS28). On the other hand, systemic inflammatory conditions can increase arginase expression in endothelial and immune cells, and therefore, authors indicate that elevated arginase levels can be due to higher turnover of these cells. Although the relationship between systemic inflammation in RA and arginase activity warrants further research, authors avail this disconnection between arginase activity and RA disease activity for the clinical practice and proposed arginase activity as a potential biomarker of increased CVD risk independent of the patient's disease state [55].

3.3. Primary Sjogren Syndrome ( $p S S)$. There is mounting evidence that primary Sjogren syndrome, similar to SLE and RA, has increased morbidity of CVD [172]. However, limited evidence is available for primary SS regarding premature atherosclerosis and endothelial dysfunction. Previous studies examining subclinical CVD measured by different techniques were heterogenous in results. Nevertheless, their results indicate a subclinical vascular damage that would explain higher CV risk [173]. There are scarcely no studies determining the eNOS function and NO generation in pSS. However, some recent data shows increased oxidative stress in pSS and association of disease with IFN-I signature, which could exert indirect effects as described above [174-176]. Therefore, pSS emerges due to the similarity to SLE and RA and also due to the fact that most patients are out on medication, as an interesting model to study atherosclerosis in autoimmune diseases.

\section{Conclusions}

The role of oxidative stress has been well established in the development and progression of atherosclerosis, and eNOS uncoupling appears to be an important mechanism contributing to increased ROS generation. Moreover, eNOS uncoupling is also mediated by excessive ROS formation ("ROS-induced ROS formation").

Chronic systemic inflammation is considered an independent $\mathrm{CV}$ risk factor, and it contributes significantly to oxidative stress. Due to the close interaction between inflammation and oxidative stress, autoimmune rheumatic diseases are associated with increased CV morbidity and mortality even when traditional risk factors are absent. However, the exact role of eNOS uncoupling in premature atherogenesis in rheumatic diseases is still not fully elucidated. Similarly, there is scarcity of data on the interactions between the NO metabolic pathway and disease-related factors. The best-studied mechanisms thus far are the depletion of eNOS cofactor $\mathrm{BH}_{4}, \mathrm{~L}$-arginine deficiency, and increase in endogenous eNOS inhibitor, ADMA. Therefore, the thorough understanding of molecular mechanisms underlying impaired NO bioavailability and eNOS dysfunction may help to identify the best and most effective approach to prevent and manage $\mathrm{CV}$ complications in rheumatic diseases.

\section{Conflicts of Interest}

The authors declare that they have no conflicts of interest to declare.

\section{References}

[1] W. Herrington, B. Lacey, P. Sherliker, J. Armitage, and S. Lewington, "Epidemiology of atherosclerosis and the potential to reduce the global burden of atherothrombotic disease," Circulation Research, vol. 118, no. 4, pp. 535-546, 2016.

[2] GBD 2015 Mortality and Causes of Death Collaborators, "Global, regional, and national age-sex specific all-cause and cause-specific mortality for 240 causes of death, 19902013: a systematic analysis for the Global Burden of Disease Study 2013," The Lancet, vol. 385, no. 9963, pp. 117-171, 2016.

[3] GBD 2013 Mortality and Causes of Death Collaborators, "Global, regional, and national age-sex specific all-cause 
and cause-specific mortality for 240 causes of death, 19902013: a systematic analysis for the Global Burden of Disease Study 2013," The Lancet, vol. 385, no. 9963, pp. 117-171, 2015.

[4] J. A. Vita and J. F. Keaney Jr., "Endothelial function: a barometer for cardiovascular risk?," Circulation, vol. 106, no. 6, pp. 640-642, 2002.

[5] J. P. Halcox, A. E. Donald, E. Ellins et al., "Endothelial function predicts progression of carotid intima-media thickness," Circulation, vol. 119, no. 7, pp. 1005-1012, 2009.

[6] H. Brunner, J. R. Cockcroft, J. Deanfield et al., "Endothelial function and dysfunction. Part II: association with cardiovascular risk factors and diseases. A statement by the Working Group on Endothelins and Endothelial Factors of the European Society of Hypertension," Journal of Hypertension, vol. 23, no. 2, pp. 233-246, 2005.

[7] M. K. Reriani, L. O. Lerman, and A. Lerman, "Endothelial function as a functional expression of cardiovascular risk factors," Biomarkers in Medicine, vol. 4, no. 3, pp. 351-360, 2010.

[8] P. O. Bonetti, L. O. Lerman, and A. Lerman, "Endothelial Dysfunction," Arteriosclerosis, Thrombosis, and Vascular Biology, vol. 23, no. 2, pp. 168-175, 2003.

[9] S. Sancheti, P. Shah, and D. S. Phalgune, "Correlation of endothelial dysfunction measured by flow-mediated vasodilatation to severity of coronary artery disease," Indian Heart Journal, vol. 70, no. 5, pp. 622-626, 2018.

[10] Q. Zhong, Q. Nong, B. Mao, X. Pan, and L. Meng, “Association of impaired vascular endothelial function with increased cardiovascular risk in asymptomatic adults," BioMed Research International, vol. 2018, Article ID 3104945, 9 pages, 2018.

[11] J. Yeboah, A. R. Folsom, G. L. Burke et al., "Predictive value of brachial flow-mediated dilation for incident cardiovascular events in a population-based study: the multi-ethnic study of atherosclerosis," Circulation, vol. 120, no. 6, pp. 502-509, 2009.

[12] I. A. Ku, J. B. Imboden, P. Y. Hsue, and P. Ganz, "Rheumatoid arthritis: model of systemic inflammation driving atherosclerosis," Circulation Journal, vol. 73, no. 6, pp. 977-985, 2009.

[13] R. Agca, S. C. Heslinga, S. Rollefstad et al., "EULAR recommendations for cardiovascular disease risk management in patients with rheumatoid arthritis and other forms of inflammatory joint disorders: 2015/2016 update," Annals of the Rheumatic Diseases, vol. 76, no. 1, pp. 17-28, 2017.

[14] M. J. L. Peters, D. P. M. Symmons, D. McCarey et al., "EULAR evidence-based recommendations for cardiovascular risk management in patients with rheumatoid arthritis and other forms of inflammatory arthritis," Annals of the Rheumatic Diseases, vol. 69, no. 2, pp. 325-331, 2010.

[15] M. F. Piepoli, A. W. Hoes, S. Agewall et al., "2016 European Guidelines on cardiovascular disease prevention in clinical practice: The Sixth Joint Task Force of the European Society of Cardiology and Other Societies on Cardiovascular Disease Prevention in Clinical Practice (constituted by representatives of 10 societies and by invited experts)Developed with the special contribution of the European Association for Cardiovascular Prevention \&amp; Rehabilitation (EACPR)," European Heart Journal, vol. 37, no. 29, pp. 2315-2381, 2016.

[16] JBS3 Board, "Joint British Societies' consensus recommendations for the prevention of cardiovascular disease (JBS3)," Heart, vol. 100, Supplement 2, pp. ii1-ii67, 2014.
[17] C. M. Quiñonez-Flores, S. A. González-Chávez, D. Del Río Nájera, and C. Pacheco-Tena, "Oxidative stress relevance in the pathogenesis of the rheumatoid arthritis: a systematic review," BioMed Research International, vol. 2016, Article ID 6097417, 14 pages, 2016.

[18] A. J. Kattoor, N. V. K. Pothineni, D. Palagiri, and J. L. Mehta, "Oxidative stress in atherosclerosis," Current Atherosclerosis Reports, vol. 19, no. 11, p. 42, 2017.

[19] X. Yang, Y. Li, Y. Li et al., "Oxidative stress-mediated atherosclerosis: mechanisms and therapies," Frontiers in Physiology, vol. 8, p. 600, 2017.

[20] K. H. Park and W. J. Park, "Endothelial dysfunction: clinical implications in cardiovascular disease and therapeutic approaches," Journal of Korean Medical Science, vol. 30, no. 9, pp. 1213-1225, 2015.

[21] T. Liu, L. Zhang, D. Joo, and S. C. Sun, "NF- $\kappa$ B signaling in inflammation," Signal Transduction and Targeted Therapy, vol. 2, no. 1, article 17023, 2017.

[22] C. Zhang, "The role of inflammatory cytokines in endothelial dysfunction," Basic Research in Cardiology, vol. 103, no. 5, pp. 398-406, 2008.

[23] C. M. Steyers III and F. J. Miller Jr., "Endothelial dysfunction in chronic inflammatory diseases," International Journal of Molecular Sciences, vol. 15, no. 7, pp. 11324-11349, 2014.

[24] M. Mudau, A. Genis, A. Lochner, and H. Strijdom, "Endothelial dysfunction: the early predictor of atherosclerosis," Cardiovascular Journal of Africa, vol. 23, no. 4, pp. 222-231, 2012.

[25] U. Förstermann and H. Li, "Therapeutic effect of enhancing endothelial nitric oxide synthase (eNOS) expression and preventing eNOS uncoupling," British Journal of Pharmacology, vol. 164, no. 2, pp. 213-223, 2011.

[26] J. Egea, I. Fabregat, Y. M. Frapart et al., "European contribution to the study of ROS: a summary of the findings and prospects for the future from the COST action BM1203 (EU-ROS)," Redox Biology, vol. 13, pp. 94-162, 2017.

[27] W. Chen, L. J. Druhan, C. A. Chen et al., "Peroxynitrite induces destruction of the tetrahydrobiopterin and heme in endothelial nitric oxide synthase: transition from reversible to irreversible enzyme inhibition," Biochemistry, vol. 49, no. 14, pp. 3129-3137, 2010.

[28] K. Venardos, W. Z. Zhang, C. Lang, and D. M. Kaye, "Effect of peroxynitrite on endothelial L-arginine transport and metabolism," The International Journal of Biochemistry \& Cell Biology, vol. 41, no. 12, pp. 2522-2527, 2009.

[29] R. Radi, "Peroxynitrite, a stealthy biological oxidant," The Journal of Biological Chemistry, vol. 288, no. 37, pp. 2646426472, 2013.

[30] S. Bartesaghi and R. Radi, "Fundamentals on the biochemistry of peroxynitrite and protein tyrosine nitration," Redox Biology, vol. 14, pp. 618-625, 2018.

[31] F. Wu and J. X. Wilson, "Peroxynitrite-dependent activation of protein phosphatase type $2 \mathrm{~A}$ mediates microvascular endothelial barrier dysfunction," Cardiovascular Research, vol. 81, no. 1, pp. 38-45, 2009.

[32] D. M. Greif, R. Kou, and T. Michel, "Site-specific dephosphorylation of endothelial nitric oxide synthase by protein phosphatase 2A: evidence for crosstalk between phosphorylation sites," Biochemistry, vol. 41, no. 52, pp. 15845-15853, 2002. 
[33] M.-H. Zou, R. A. Cohen, and V. Ullrich, "Peroxynitrite and vascular endothelial dysfunction in diabetes mellitus," Endothelium, vol. 11, no. 2, pp. 89-97, 2004.

[34] M. Zhang, P. Song, J. Xu, and M. H. Zou, "Activation of $\mathrm{NAD}(\mathrm{P}) \mathrm{H}$ oxidases by thromboxane $\mathrm{A}_{2}$ receptor uncouples endothelial nitric oxide synthase," Arteriosclerosis, Thrombosis, and Vascular Biology, vol. 31, no. 1, pp. 125-132, 2011.

[35] H. Botti, A. Trostchansky, C. Batthyány, and H. Rubbo, "Reactivity of peroxynitrite and nitric oxide with LDL," IUBMB Life, vol. 57, no. 6, pp. 407-412, 2005.

[36] A. Pirillo, G. D. Norata, and A. L. Catapano, "LOX-1, OxLDL, and atherosclerosis," Mediators of Inflammation, vol. 2013, Article ID 152786, 12 pages, 2013.

[37] U. Förstermann and W. C. Sessa, "Nitric oxide synthases: regulation and function," European Heart Journal, vol. 33, no. 7, pp. 829-837, 2012.

[38] K. Wada, K. Inoue, and M. Hagiwara, "Identification of methylated proteins by protein arginine $\mathrm{N}$-methyltransferase 1, PRMT1, with a new expression cloning strategy," Biochimica et Biophysica Acta (BBA) - Molecular Cell Research, vol. 1591, no. 1-3, pp. 1-10, 2002.

[39] T. Teerlink, "ADMA metabolism and clearance," Vascular Medicine, vol. 10, Supplement 1, pp. S73-S81, 2006.

[40] Y. L. Tain and C. N. Hsu, “Toxic dimethylarginines: asymmetric dimethylarginine (ADMA) and symmetric dimethylarginine (SDMA)," Toxins, vol. 9, no. 3, p. 92, 2017.

[41] J. P. Cooke, "Asymmetrical dimethylarginine: the Uber marker?," Circulation, vol. 109, no. 15, pp. 1813-1818, 2004.

[42] N. Melikian, S. B. Wheatcroft, O. S. Ogah et al., "Asymmetric dimethylarginine and reduced nitric oxide bioavailability in young Black African men," Hypertension, vol. 49, no. 4, pp. 873-877, 2007.

[43] R. Schnabel, S. Blankenberg, E. Lubos et al., "Asymmetric dimethylarginine and the risk of cardiovascular events and death in patients with coronary artery disease: results from the AtheroGene Study," Circulation Research, vol. 97, no. 5, pp. e53-e59, 2005.

[44] P. Willeit, D. F. Freitag, J. A. Laukkanen et al., "Asymmetric dimethylarginine and cardiovascular risk: systematic review and meta-analysis of 22 prospective studies," Journal of the American Heart Association, vol. 4, no. 6, article e001833, 2015.

[45] S. Zhou, Q. Zhu, X. Li et al., "Asymmetric dimethylarginine and all-cause mortality: a systematic review and metaanalysis," Scientific Reports, vol. 7, no. 1, article 44692, 2017.

[46] J. Jacobi, R. Maas, A. J. Cardounel et al., "Dimethylarginine dimethylaminohydrolase overexpression ameliorates atherosclerosis in apolipoprotein E-deficient mice by lowering asymmetric dimethylarginine," The American Journal of Pathology, vol. 176, no. 5, pp. 2559-2570, 2010.

[47] R. H. Böger, S. M. Bode-Böger, A. Szuba et al., "Asymmetric dimethylarginine (ADMA): a novel risk factor for endothelial Dysfunction," Circulation, vol. 98, no. 18, pp. 1842-1847, 1998.

[48] A. J. Pope, K. Karuppiah, and A. J. Cardounel, "Role of the PRMT-DDAH-ADMA axis in the regulation of endothelial nitric oxide production," Pharmacological Research, vol. 60, no. 6, pp. 461-465, 2009.

[49] C. Antoniades, C. Shirodaria, P. Leeson et al., "Association of plasma asymmetrical dimethylarginine (ADMA) with elevated vascular superoxide production and endothelial nitric oxide synthase uncoupling: implications for endothelial function in human atherosclerosis," European Heart Journal, vol. 30, no. 9, pp. 1142-1150, 2009.

[50] K. Y. Lin, A. Ito, T. Asagami et al., "Impaired nitric oxide synthase pathway in diabetes mellitus: role of asymmetric dimethylarginine and dimethylarginine dimethylaminohydrolase," Circulation, vol. 106, no. 8, pp. 987-992, 2002.

[51] M. C. Stühlinger, P. S. Tsao, J. H. Her, M. Kimoto, R. F. Balint, and J. P. Cooke, "Homocysteine impairs the nitric oxide synthase Pathway," Circulation, vol. 104, no. 21, pp. 2569-2575, 2001.

[52] A. Ito, P. S. Tsao, S. Adimoolam, M. Kimoto, T. Ogawa, and J. P. Cooke, "Novel mechanism for endothelial dysfunction," Circulation, vol. 99, no. 24, pp. 3092-3095, 1999.

[53] I. V. Smirnova, T. Sawamura, and M. S. Goligorsky, "Upregulation of lectin-like oxidized low-density lipoprotein receptor-1 (LOX-1) in endothelial cells by nitric oxide deficiency," American Journal of Physiology-Renal Physiology, vol. 287, no. 1, pp. F25-F32, 2004.

[54] I. V. Smirnova, M. Kajstura, T. Sawamura, and M. S. Goligorsky, "Asymmetric dimethylarginine upregulates LOX-1 in activated macrophages: role in foam cell formation," American Journal of Physiology-Heart and Circulatory Physiology, vol. 287, no. 2, pp. H782-H790, 2004.

[55] U. M. Chandrasekharan, Z. Wang, Y. Wu et al., "Elevated levels of plasma symmetric dimethylarginine and increased arginase activity as potential indicators of cardiovascular comorbidity in rheumatoid arthritis," Arthritis Research \& Therapy, vol. 20, no. 1, p. 123, 2018.

[56] M. Turiel, F. Atzeni, L. Tomasoni et al., "Non-invasive assessment of coronary flow reserve and ADMA levels: a case-control study of early rheumatoid arthritis patients," Rheumatology, vol. 48, no. 7, pp. 834-839, 2009.

[57] A. Radhakutty, B. L. Mangelsdorf, S. M. Drake et al., "Opposing effects of rheumatoid arthritis and low dose prednisolone on arginine metabolomics," Atherosclerosis, vol. 266, pp. 190195, 2017.

[58] K. Angel, S. A. Provan, P. Mowinckel, I. Seljeflot, T. K. Kvien, and D. Atar, "The 1-arginine/asymmetric dimethylarginine ratio is improved by anti-Tumor Necrosis Factor- $\alpha$ therapy in inflammatory arthropathies. Associations with aortic stiffness," Atherosclerosis, vol. 225, no. 1, pp. 160-165, 2012.

[59] C. Antoniades, M. Demosthenous, D. Tousoulis et al., "Role of asymmetrical dimethylarginine in inflammation-induced endothelial dysfunction in human atherosclerosis," Hypertension, vol. 58, no. 1, pp. 93-98, 2011.

[60] M. Di Franco, F. R. Spinelli, A. Metere et al., "Serum levels of asymmetric dimethylarginine and apelin as potential markers of vascular endothelial dysfunction in early rheumatoid arthritis," Mediators of Inflammation, vol. 2012, Article ID 347268, 7 pages, 2012.

[61] A. Sandoo, T. Dimitroulas, J. Veldhuijzen van Zanten et al., "Lack of association between asymmetric dimethylarginine and in vivo microvascular and macrovascular endothelial function in patients with rheumatoid arthritis," Clinical and Experimental Rheumatology, vol. 30, no. 3, pp. 388-396, 2012.

[62] T. Dimitroulas, J. Hodson, A. Sandoo, J. Smith, and G. D. Kitas, "Endothelial injury in rheumatoid arthritis: a crosstalk between dimethylarginines and systemic inflammation," Arthritis Research \& Therapy, vol. 19, no. 1, p. 32, 2017. 
[63] A. Surdacki, J. Martens-Lobenhoffer, A. Wloch et al., "Plasma asymmetric dimethylarginine is related to anticitrullinated protein antibodies in rheumatoid arthritis of short duration," Metabolism, vol. 58, no. 3, pp. 316-318, 2009.

[64] D. Spasovski, A. Latifi, B. Osmani et al., "Determination of the diagnostic values of asymmetric dimethylarginine as an indicator for evaluation of the endothelial dysfunction in patients with rheumatoid arthritis," Arthritis, vol. 2013, Article ID 818037, 10 pages, 2013.

[65] T. Şentürk, N. Yılmaz, G. Sargın, K. Köseoğlu, and Ç. Yenisey, "Relationship between asymmetric dimethylarginine and endothelial dysfunction in patients with rheumatoid arthritis," European Journal of Rheumatology, vol. 3, no. 3, pp. 106-108, 2016.

[66] B. Kwaśny-Krochin, P. Głuszko, and A. Undas, "Plasma asymmetric dimethylarginine in active rheumatoid arthritis: links with oxidative stress and inflammation," Polskie Archiwum Medycyny Wewnętrznej, vol. 122, no. 6, pp. 270-276, 2012.

[67] A. Surdacki, J. Martens-Lobenhoffer, A. Wloch et al., "Elevated plasma asymmetric dimethyl-L-arginine levels are linked to endothelial progenitor cell depletion and carotid atherosclerosis in rheumatoid arthritis," Arthritis and Rheumatism, vol. 56, no. 3, pp. 809-819, 2007.

[68] T. Dimitroulas, A. Sandoo, J. Hodson, J. P. Smith, and G. D. Kitas, "In vivo microvascular and macrovascular endothelial function is not associated with circulating dimethylarginines in patients with rheumatoid arthritis: a prospective analysis of the DRACCO cohort," Scandinavian Journal of Clinical and Laboratory Investigation, vol. 76, no. 4, pp. 331-337, 2016.

[69] J. L. Jiang, D. J. Jiang, Y. H. Tang, N. S. Li, H. W. Deng, and Y. J. Li, "Effect of simvastatin on endothelium-dependent vaso-relaxation and endogenous nitric oxide synthase inhibitor," Acta Pharmacologica Sinica, vol. 25, no. 7, pp. 893-901, 2004.

[70] G. Werner-Felmayer, E. R. Werner, D. Fuchs et al., "Pteridine biosynthesis in human endothelial cells. Impact on nitric oxide-mediated formation of cyclic GMP," The Journal of Biological Chemistry, vol. 268, no. 3, pp. 1842-1846, 1993.

[71] W. Shi, C. J. Meininger, T. E. Haynes, K. Hatakeyama, and $\mathrm{G}$. Wu, "Regulation of tetrahydrobiopterin synthesis and bioavailability in endothelial cells," Cell Biochemistry and Biophysics, vol. 41, no. 3, pp. 415-434, 2004.

[72] M. J. Crabtree and K. M. Channon, "Synthesis and recycling of tetrahydrobiopterin in endothelial function and vascular disease," Nitric Oxide, vol. 25, no. 2, pp. 81-88, 2011.

[73] U. Landmesser, S. Dikalov, S. R. Price et al., "Oxidation of tetrahydrobiopterin leads to uncoupling of endothelial cell nitric oxide synthase in hypertension," The Journal of Clinical Investigation, vol. 111, no. 8, pp. 1201-1209, 2003.

[74] U. Förstermann, N. Xia, and H. Li, "Roles of vascular oxidative stress and nitric oxide in the pathogenesis of atherosclerosis," Circulation Research, vol. 120, no. 4, pp. 713-735, 2017.

[75] M. J. Crabtree, C. L. Smith, G. Lam, M. S. Goligorsky, and S. S. Gross, "Ratio of 5,6,7,8-tetrahydrobiopterin to 7,8-dihydrobiopterin in endothelial cells determines glucoseelicited changes in NO vs. superoxide production by eNOS," American Journal of Physiology-Heart and Circulatory Physiology, vol. 294, no. 4, pp. H1530-H1540, 2008.
[76] M. J. Crabtree, A. L. Tatham, A. B. Hale, N. J. Alp, and K. M. Channon, "Critical role for tetrahydrobiopterin recycling by dihydrofolate reductase in regulation of endothelial nitricoxide synthase coupling: relative importance of the de novo biopterin synthesis versus salvage pathways," The Journal of Biological Chemistry, vol. 284, no. 41, pp. 28128-28136, 2009.

[77] M. J. Crabtree, A. L. Tatham, Y. Al-Wakeel et al., "Quantitative regulation of intracellular endothelial nitric-oxide synthase (eNOS) coupling by both tetrahydrobiopterineNOS stoichiometry and biopterin redox status: insights from cells with tet-regulated GTP cyclohydrolase I expression," The Journal of Biological Chemistry, vol. 284, no. 2, pp. 1136-1144, 2009.

[78] P. Klatt, M. Schmid, E. Leopold, K. Schmidt, E. R. Werner, and B. Mayer, "The pteridine binding site of brain nitric oxide synthase. Tetrahydrobiopterin binding kinetics, specificity, and allosteric interaction with the substrate domain," The Journal of Biological Chemistry, vol. 269, no. 19, pp. 13861-13866, 1994.

[79] M. Ishii, S. Shimizu, T. Nagai, K. Shiota, Y. Kiuchi, and T. Yamamoto, "Stimulation of tetrahydrobiopterin synthesis induced by insulin: possible involvement of phosphatidylinositol 3-kinase," The International Journal of Biochemistry \& Cell Biology, vol. 33, no. 1, pp. 65-73, 2001.

[80] A. L. Moens and D. A. Kass, "Tetrahydrobiopterin and cardiovascular disease," Arteriosclerosis, Thrombosis, and Vascular Biology, vol. 26, no. 11, pp. 2439-2444, 2006.

[81] K. Chalupsky and H. Cai, "Endothelial dihydrofolate reductase: critical for nitric oxide bioavailability and role in angiotensin II uncoupling of endothelial nitric oxide synthase," Proceedings of the National Academy of Sciences of the United States of America, vol. 102, no. 25, pp. 9056-9061, 2005.

[82] M. J. Crabtree, A. B. Hale, and K. M. Channon, "Dihydrofolate reductase protects endothelial nitric oxide synthase from uncoupling in tetrahydrobiopterin deficiency," Free Radical Biology \& Medicine, vol. 50, no. 11, pp. 16391646, 2011.

[83] G. L. Pierce and T. J. Larocca, "Reduced vascular tetrahydrobiopterin (BH4) and endothelial function with ageing: is it time for a chronic $\mathrm{BH} 4$ supplementation trial in middleaged and older adults?," The Journal of Physiology, vol. 586, no. 11, pp. 2673-2674, 2008.

[84] D. M. McDonald, K. S. Edgar, T. A. Gardiner, and Z. S. Katusic, "BH4 supplementation improves vascular integrity during hyperoxia in oxygen induced retinopathy," Investigative Ophthalmology \& Visual Science, vol. 55, article 5376, 2014.

[85] S. Ueda, H. Matsuoka, H. Miyazaki, M. Usui, S. Okuda, and T. Imaizumi, "Tetrahydrobiopterin restores endothelial function in long-term smokers," Journal of the American College of Cardiology, vol. 35, no. 1, pp. 71-75, 2000.

[86] E. Stroes, J. Kastelein, F. Cosentino et al., "Tetrahydrobiopterin restores endothelial function in hypercholesterolemia," The Journal of Clinical Investigation, vol. 99, no. 1, pp. 41-46, 1997.

[87] T. Heitzer, K. Krohn, S. Albers, and T. Meinertz, "Tetrahydrobiopterin improves endothelium-dependent vasodilation by increasing nitric oxide activity in patients with type II diabetes mellitus," Diabetologia, vol. 43, no. 11, pp. 1435-1438, 2000 . 
[88] T. Heitzer, C. Brockhoff, B. Mayer et al., "Tetrahydrobiopterin improves endothelium-dependent vasodilation in chronic smokers : evidence for a dysfunctional nitric oxide synthase," Circulation Research, vol. 86, no. 2, pp. E36-E41, 2000.

[89] Q. Wang, M. Yang, H. Xu, and J. Yu, "Tetrahydrobiopterin improves endothelial function in cardiovascular disease: a systematic review," Evidence-based Complementary and Alternative Medicine, vol. 2014, Article ID 850312, 7 pages, 2014.

[90] D. Hurlimann, G. Noll, C. D. Gatti et al., "Oral treatment with tetrahydrobiopterin reverses endothelial dysfunction and oxidative stress in hypercholesterolemia," Circulation, vol. 112, pp. U192-U193, 2005.

[91] T. Nyström, A. Nygren, and A. Sjöholm, “Tetrahydrobiopterin increases insulin sensitivity in patients with type 2 diabetes and coronary heart disease," American Journal of Physiology-Endocrinology and Metabolism, vol. 287, no. 5, pp. E919-E925, 2004.

[92] K. L. Moreau, A. Meditz, K. D. Deane, and W. M. Kohrt, "Tetrahydrobiopterin improves endothelial function and decreases arterial stiffness in estrogen-deficient postmenopausal women," American Journal of Physiology-Heart and Circulatory Physiology, vol. 302, no. 5, pp. H1211-H1218, 2012.

[93] Y. Higashi, S. Sasaki, K. Nakagawa et al., “Tetrahydrobiopterin enhances forearm vascular response to acetylcholine in both normotensive and hypertensive individuals," American Journal of Hypertension, vol. 15, no. 4, pp. 326-332, 2002.

[94] B. A. Taylor, A. L. Zaleski, E. A. Dornelas, and P. D. Thompson, "The impact of tetrahydrobiopterin administration on endothelial function before and after smoking cessation in chronic smokers," Hypertension Research, vol. 39, no. 3, pp. 144-150, 2016.

[95] L. Li, W. Chen, A. Rezvan, H. Jo, and D. G. Harrison, “Tetrahydrobiopterin deficiency and nitric oxide synthase uncoupling contribute to atherosclerosis induced by disturbed flow," Arteriosclerosis, Thrombosis, and Vascular Biology, vol. 31, no. 7, pp. 1547-1554, 2011.

[96] Y. Haruna, Y. Morita, N. Komai et al., "Endothelial dysfunction in rat adjuvant-induced arthritis: vascular superoxide production by $\mathrm{NAD}(\mathrm{P}) \mathrm{H}$ oxidase and uncoupled endothelial nitric oxide synthase," Arthritis and Rheumatism, vol. 54, no. 6, pp. 1847-1855, 2006.

[97] Y. Haruna, Y. Morita, T. Yada, M. Satoh, D. A. Fox, and N. Kashihara, "Fluvastatin reverses endothelial dysfunction and increased vascular oxidative stress in rat adjuvantinduced arthritis," Arthritis and Rheumatism, vol. 56, no. 6, pp. 1827-1835, 2007.

[98] K. M. Mäki-Petäjä, L. Day, J. Cheriyan et al., “Tetrahydrobiopterin supplementation improves endothelial function but does not alter aortic stiffness in patients with rheumatoid arthritis," Journal of the American Heart Association, vol. 5, no. 2, 2016.

[99] K. M. Mäki-Petäjä, J. Cheriyan, A. D. Booth et al., "Inducible nitric oxide synthase activity is increased in patients with rheumatoid arthritis and contributes to endothelial dysfunction," International Journal of Cardiology, vol. 129, no. 3, pp. 399-405, 2008.

[100] Y. Rikitake and J. K. Liao, "Rho GTPases, statins, and nitric oxide," Circulation Research, vol. 97, no. 12, pp. 1232-1235, 2005.
[101] P. Totoson, K. Maguin-Gaté, A. Prigent-Tessier et al., "Etanercept improves endothelial function via pleiotropic effects in rat adjuvant-induced arthritis," Rheumatology, vol. 55, no. 7, pp. 1308-1317, 2016.

[102] C. F. Spurlock III, H. M. Gass IV, C. J. Bryant, B. C. Wells, N. J. Olsen, and T. M. Aune, "Methotrexate-mediated inhibition of nuclear factor $\kappa \mathrm{B}$ activation by distinct pathways in $\mathrm{T}$ cells and fibroblast-like synoviocytes," Rheumatology, vol. 54, no. 1, pp. 178-187, 2015.

[103] W. Chen, L. Li, T. Brod et al., "Role of increased guanosine triphosphate cyclohydrolase-1 expression and tetrahydrobiopterin levels upon T cell activation," The Journal of Biological Chemistry, vol. 286, no. 16, pp. 13846-13851, 2011.

[104] D. Popov, G. Costache, A. Georgescu, and M. Enache, "Beneficial effects of $\mathrm{L}$-arginine supplementation in experimental hyperlipemia-hyperglycemia in the hamster," Cell and Tissue Research, vol. 308, no. 1, pp. 109-120, 2002.

[105] N. Pahlavani, M. Jafari, M. Rezaei et al., "L-Arginine supplementation and risk factors of cardiovascular diseases in healthy men: a double-blind randomized clinical trial," F1000Res, vol. 3, p. 306, 2014.

[106] J. P. Lekakis, S. Papathanassiou, T. G. Papaioannou et al., "Oral L-arginine improves endothelial dysfunction in patients with essential hypertension," International Journal of Cardiology, vol. 86, no. 2-3, pp. 317-323, 2002.

[107] A. Chauhan, R. S. More, P. A. Mullins, G. Taylor, M. C. Petch, and P. M. Schofield, "Aging-associated endothelial dysfunction in humans is reversed by L-arginine," Journal of the American College of Cardiology, vol. 28, no. 7, pp. 17961804, 1996.

[108] J. Y. Dong, L. Q. Qin, Z. Zhang et al., "Effect of oral L-arginine supplementation on blood pressure: a meta-analysis of randomized, double-blind, placebo-controlled trials," American Heart Journal, vol. 162, no. 6, pp. 959-965, 2011.

[109] P. Clarkson, M. R. Adams, A. J. Powe et al., "Oral L-arginine improves endothelium-dependent dilation in hypercholesterolemic young adults," The Journal of Clinical Investigation, vol. 97, no. 8, pp. 1989-1994, 1996.

[110] H. Drexler, A. M. Zeiher, K. Meinzer, and H. Just, "Correction of endothelial dysfunction in coronary microcirculation of hypercholesterolaemic patients by L-arginine," The Lancet, vol. 338, no. 8782-8783, pp. 1546-1550, 1991.

[111] R. H. Boger, S. M. Bode-Boger, A. Mugge et al., "Supplementation of hypercholesterolaemic rabbits with L-arginine reduces the vascular release of superoxide anions and restores NO production," Atherosclerosis, vol. 117, no. 2, pp. 273-284, 1995.

[112] G. Siasos, D. Tousoulis, C. Vlachopoulos et al., "The impact of oral L-arginine supplementation on acute smokinginduced endothelial injury and arterial performance," American Journal of Hypertension, vol. 22, no. 6, pp. 586-592, 2009.

[113] Y. Xiong, M. F. Fru, Y. Yu, J. P. Montani, X. F. Ming, and Z. Yang, "Long term exposure to L-arginine accelerates endothelial cell senescence through arginase-II and S6K1 signaling," Aging, vol. 6, no. 5, pp. 369-379, 2014.

[114] J. Rodrigues-Krause, M. Krause, I. M. G. D. Rocha, D. Umpierre, and A. P. T. Fayh, "Association of l-arginine supplementation with markers of endothelial function in patients with cardiovascular or metabolic disorders: a systematic review and meta-analysis," Nutrients, vol. 11, no. 1, p. 15, 2019. 
[115] H. A. Walker, E. McGing, I. Fisher et al., "Endotheliumdependent vasodilation is independent of the plasma L-arginine/ADMA ratio in men with stable angina: lack of effect of oral L-arginine on endothelial function, oxidative stress and exercise performance," Journal of the American College of Cardiology, vol. 38, no. 2, pp. 499-505, 2001.

[116] T. S. Alvares, C. A. Conte-Junior, J. T. Silva, and V. M. F. Paschoalin, "L-Arginine does not improve biochemical and hormonal response in trained runners after 4 weeks of supplementation," Nutrition Research, vol. 34, no. 1, pp. 31-39, 2014.

[117] Z. Bahadoran, P. Mirmiran, Z. Tahmasebinejad, and F. Azizi, "Dietary L-arginine intake and the incidence of coronary heart disease: Tehran lipid and glucose study," Nutrition \& Metabolism, vol. 13, no. 1, p. 23, 2016.

[118] T. Sun, W. B. Zhou, X. P. Luo, Y. L. Tang, and H. M. Shi, "Oral L-arginine supplementation in acute myocardial infarction therapy: a meta-analysis of randomized controlled trials," Clinical Cardiology, vol. 32, no. 11, pp. 649-652, 2009.

[119] T. S. Alvares, C. A. Conte-Junior, J. T. Silva, and V. M. Paschoalin, "Acute L-arginine supplementation does not increase nitric oxide production in healthy subjects," Nutrition \& Metabolism, vol. 9, no. 1, p. 54, 2012.

[120] J. Loscalzo, "Adverse effects of Supplementall-Arginine in Atherosclerosis," Arteriosclerosis, Thrombosis, and Vascular Biology, vol. 23, no. 1, pp. 3-5, 2003.

[121] Y. C. Luiking, G. A. M. ten Have, R. R. Wolfe, and N. E. P. Deutz, "Arginine de novo and nitric oxide production in disease states," American Journal of Physiology-Endocrinology and Metabolism, vol. 303, no. 10, pp. E1177-E1189, 2012.

[122] G. Wu, F. W. Bazer, T. A. Davis et al., "Arginine metabolism and nutrition in growth, health and disease," Amino Acids, vol. 37, no. 1, pp. 153-168, 2009.

[123] R. B. Caldwell, H. A. Toque, S. P. Narayanan, and R. W. Caldwell, "Arginase: an old enzyme with new tricks," Trends in Pharmacological Sciences, vol. 36, no. 6, pp. 395-405, 2015.

[124] J. Pernow and C. Jung, "The emerging role of arginase in endothelial dysfunction in diabetes," Current Vascular Pharmacology, vol. 14, no. 2, pp. 155-162, 2016.

[125] R. Lucas, D. Fulton, R. W. Caldwell, and M. J. Romero, "Arginase in the vascular endothelium: friend or foe?," Frontiers in Immunology, vol. 5, p. 589, 2014.

[126] F. K. Johnson, K. J. Peyton, X. M. Liu et al., “Arginase promotes endothelial dysfunction and hypertension in obese rats," Obesity, vol. 23, no. 2, pp. 383-390, 2015.

[127] J. Pernow and C. Jung, "Arginase as a potential target in the treatment of cardiovascular disease: reversal of arginine steal?," Cardiovascular Research, vol. 98, no. 3, pp. 334-343, 2013.

[128] L. A. Rabelo, F. O. Ferreira, V. Nunes-Souza, L. J. S. Fonseca, and M. O. F. Goulart, "Arginase as a critical prooxidant mediator in the binomial endothelial dysfunction-atherosclerosis," Oxidative Medicine and Cellular Longevity, vol. 2015, Article ID 924860, 12 pages, 2015.

[129] W. S. Shin, D. E. Berkowitz, and S. W. Ryoo, "Increased arginase II activity contributes to endothelial dysfunction through endothelial nitric oxide synthase uncoupling in aged mice," Experimental \& Molecular Medicine, vol. 44, no. 10, pp. 594-602, 2012.

[130] S. Chandra, M. J. Romero, A. Shatanawi, A. M. Alkilany, R. B. Caldwell, and R. W. Caldwell, "Oxidative species increase arginase activity in endothelial cells through the RhoA/Rho kinase pathway," British Journal of Pharmacology, vol. 165, no. 2, pp. 506-519, 2012.

[131] S. Sankaralingam, H. Xu, and S. T. Davidge, "Arginase contributes to endothelial cell oxidative stress in response to plasma from women with preeclampsia," Cardiovascular Research, vol. 85, no. 1, pp. 194-203, 2010.

[132] J. Suwanpradid, M. Rojas, M. A. Behzadian, R. W. Caldwell, and R. B. Caldwell, "Arginase 2 deficiency prevents oxidative stress and limits hyperoxia-induced retinal vascular degeneration," PLoS One, vol. 9, no. 11, article e110604, 2014.

[133] K. K. McDonald, S. Zharikov, E. R. Block, and M. S. Kilberg, "A caveolar complex between the cationic amino acid transporter 1 and endothelial nitric-oxide synthase may explain the arginine paradox," The Journal of Biological Chemistry, vol. 272, no. 50, pp. 31213-31216, 1997.

[134] K. J. Peyton, D. Ensenat, M. A. Azam et al., "Arginase promotes neointima formation in rat injured carotid arteries," Arteriosclerosis, Thrombosis, and Vascular Biology, vol. 29, no. 4, pp. 488-494, 2009.

[135] W. Durante, F. K. Johnson, and R. A. Johnson, “Arginase: a critical regulator of nitric oxide synthesis and vascular function," Clinical and Experimental Pharmacology \& Physiology, vol. 34, no. 9, pp. 906-911, 2007.

[136] H. Li and U. Forstermann, "Pharmacological prevention of eNOS uncoupling," Current Pharmaceutical Design, vol. 20, no. 22, pp. 3595-3606, 2014.

[137] C. Zhu, Y. Yu, J. P. Montani, X. F. Ming, and Z. Yang, "Arginase-I enhances vascular endothelial inflammation and senescence through eNOS-uncoupling," BMC Research Notes, vol. 10, no. 1, p. 82, 2017.

[138] C. Prati, A. Berthelot, D. Wendling, and C. Demougeot, "Endothelial dysfunction in rat adjuvant-induced arthritis: up-regulation of the vascular arginase pathway," Arthritis and Rheumatism, vol. 63, no. 8, pp. 2309-2317, 2011.

[139] C. Prati, A. Berthelot, B. Kantelip, D. Wendling, and C. Demougeot, "Treatment with the arginase inhibitor $\mathrm{Nw}$-hydroxy-nor-L-arginine restores endothelial function in rat adjuvant-induced arthritis," Arthritis Research \& Therapy, vol. 14, no. 3, p. R130, 2012.

[140] L. A. Holowatz, L. Santhanam, A. Webb, D. E. Berkowitz, and W. L. Kenney, "Oral atorvastatin therapy restores cutaneous microvascular function by decreasing arginase activity in hypercholesterolaemic humans," The Journal of Physiology, vol. 589, no. 8, pp. 2093-2103, 2011.

[141] F. Verhoeven, P. Totoson, C. Marie et al., "Diclofenac but not celecoxib improves endothelial function in rheumatoid arthritis: a study in adjuvant-induced arthritis," Atherosclerosis, vol. 266, pp. 136-144, 2017.

[142] M. McMahon, B. H. Hahn, and B. J. Skaggs, “Systemic lupus erythematosus and cardiovascular disease: prediction and potential for therapeutic intervention," Expert Review of Clinical Immunology, vol. 7, no. 2, pp. 227-241, 2011.

[143] V. Teixeira and L. S. Tam, "Novel insights in systemic lupus erythematosus and atherosclerosis," Frontiers in Medicine, vol. 4, p. 262, 2018.

[144] L. B. Lewandowski and M. J. Kaplan, "Update on cardiovascular disease in lupus," Current Opinion in Rheumatology, vol. 28, no. 5, pp. 468-476, 2016.

[145] M. J. Roman, B. A. Shanker, A. Davis et al., "Prevalence and correlates of accelerated atherosclerosis in systemic lupus 
erythematosus," The New England Journal of Medicine, vol. 349, no. 25, pp. 2399-2406, 2003.

[146] D. Mauro and A. Nerviani, "Endothelial dysfunction in systemic lupus erythematosus: pathogenesis, assessment and therapeutic opportunities," Reviews on Recent Clinical Trials, vol. 13, no. 3, pp. 192-198, 2018.

[147] A. Mak, N. Y. Kow, H. Schwarz, L. Gong, S. H. Tay, and L. H. Ling, "Endothelial dysfunction in systemic lupus erythematosus - a case-control study and an updated meta-analysis and meta-regression," Scientific Reports, vol. 7, no. 1, p. 7320, 2017.

[148] J. N. Jones Buie and J. C. Oates, "Role of interferon alpha in endothelial dysfunction: insights into endothelial nitric oxide synthase-related mechanisms," The American Journal of the Medical Sciences, vol. 348, no. 2, pp. 168-175, 2014.

[149] J. M. Kahlenberg and M. J. Kaplan, "Mechanisms of premature atherosclerosis in rheumatoid arthritis and lupus," Annual Review of Medicine, vol. 64, no. 1, pp. 249-263, 2013.

[150] J. A. Reynolds, D. W. Ray, L. A. H. Zeef, T. O'Neill, I. N. Bruce, and M. Y. Alexander, "The effect of type 1 IFN on human aortic endothelial cell function in vitro: relevance to systemic lupus erythematosus," Journal of Interferon \& Cytokine Research, vol. 34, no. 5, pp. 404-412, 2014.

[151] J. J. Buie, L. L. Renaud, R. Muise-Helmericks, and J. C. Oates, "IFN- $\alpha$ negatively regulates the expression of endothelial nitric oxide synthase and nitric oxide production: implications for systemic lupus erythematosus," Journal of Immunology, vol. 199, no. 6, pp. 1979-1988, 2017.

[152] J. C. Felger, L. Li, P. J. Marvar et al., "Tyrosine metabolism during interferon-alpha administration: association with fatigue and CSF dopamine concentrations," Brain, Behavior, and Immunity, vol. 31, pp. 153-160, 2013.

[153] T. Kitagami, K. Yamada, H. Miura, R. Hashimoto, T. Nabeshima, and T. Ohta, "Mechanism of systemically injected interferon-alpha impeding monoamine biosynthesis in rats: role of nitric oxide as a signal crossing the blood-brain barrier," Brain Research, vol. 978, no. 1-2, pp. 104-114, 2003.

[154] D. Fekkes, M. Bannink, W. H. J. Kruit et al., "Influence of pegylated interferon-alpha therapy on plasma levels of citrulline and arginine in melanoma patients," Amino Acids, vol. 32, no. 1, pp. 121-126, 2007.

[155] D. Fekkes, A. R. van Gool, M. Bannink et al., "Nitric oxide production and monoamine oxidase activity in cancer patients during interferon-alpha therapy," Amino Acids, vol. 37, no. 4, pp. 703-708, 2009.

[156] H. Wu, Y. Zhen, Z. Ma et al., "Arginase-1-dependent promotion of TH17 differentiation and disease progression by MDSCs in systemic lupus erythematosus," Science Translational Medicine, vol. 8, no. 331, article 331ra40, 2016.

[157] T. Takahashi and R. C. Harris, "Role of endothelial nitric oxide synthase in diabetic nephropathy: lessons from diabetic eNOS knockout mice," Journal Diabetes Research, vol. 2014, article 590541, pp. 1-17, 2014.

[158] C. E. Weckerle, B. S. Franek, J. A. Kelly et al., "Network analysis of associations between serum interferon- $\alpha$ activity, autoantibodies, and clinical features in systemic lupus erythematosus," Arthritis and Rheumatism, vol. 63, no. 4, pp. 10441053, 2011.

[159] M. Perna, M. J. Roman, D. R. Alpert et al., "Relationship of asymmetric dimethylarginine and homocysteine to vascular aging in systemic lupus erythematosus patients," Arthritis and Rheumatism, vol. 62, no. 6, pp. 1718-1722, 2010.
[160] K. H. Sun, S. J. Tang, Y. S. Wang, W. J. Lin, and R. I. You, "Autoantibodies to dsDNA cross-react with the arginineglycine-rich domain of heterogeneous nuclear ribonucleoprotein A2 (hnRNP A2) and promote methylation of hnRNP A2," Rheumatology, vol. 42, no. 1, pp. 154-161, 2003.

[161] I. E. Bultink, T. Teerlink, J. A. Heijst, B. A. Dijkmans, and A. E. Voskuyl, "Raised plasma levels of asymmetric dimethylarginine are associated with cardiovascular events, disease activity, and organ damage in patients with systemic lupus erythematosus," Annals of the Rheumatic Diseases, vol. 64, no. 9, pp. 1362-1365, 2005.

[162] A. N. Kiani, J. A. Mahoney, and M. Petri, "Asymmetric dimethylarginine is a marker of poor prognosis and coronary calcium in systemic lupus erythematosus," The Journal of Rheumatology, vol. 34, no. 7, pp. 1502-1505, 2007.

[163] A. Sandoo, J. J. C. S. Veldhuijzen van Zanten, G. S. Metsios, D. Carroll, and G. D. Kitas, "Vascular function and morphology in rheumatoid arthritis: a systematic review," Rheumatology, vol. 50, no. 11, pp. 2125-2139, 2011.

[164] F. Ursini, C. Leporini, F. Bene et al., "Anti-TNF-alpha agents and endothelial function in rheumatoid arthritis: a systematic review and meta-analysis," Scientific Reports, vol. 7, no. 1, article 5346, 2017.

[165] A. Sandoo, T. Dimitroulas, J. Hodson, J. P. Smith, K. M. Douglas, and G. D. Kitas, "Cumulative inflammation associates with asymmetric dimethylarginine in rheumatoid arthritis: a 6 year follow-up study," Rheumatology, vol. 54, no. 7, pp. 1145-1152, 2015.

[166] F. R. Spinelli, M. Di Franco, A. Metere et al., "Decrease of asymmetric dimethyl arginine after anti-TNF therapy in patients with rheumatoid arthritis," Drug Development Research, vol. 75, Supplement 1, pp. S67-S69, 2014.

[167] A. Sandoo, T. Dimitroulas, T. E. Toms et al., "Clinical remission following treatment with tumour necrosis factor-alpha antagonists is not accompanied by changes in asymmetric dimethylarginine in patients with rheumatoid arthritis," Clinical Biochemistry, vol. 45, no. 16-17, pp. 1399-1403, 2012.

[168] D. Spasovski and T. Sotirova, "Link between dimethyl arginine derivats and Acpa antibodies in patients with rheumatoid arthritis," Interdisciplinary Journal of Microinflammation, vol. 1, no. 2, 2014.

[169] T. Dimitroulas, A. Sandoo, J. J. J. C. S. V. van Zanten et al., "Predictors of asymmetric dimethylarginine levels in patients with rheumatoid arthritis: the role of insulin resistance," Scandinavian Journal of Rheumatology, vol. 42, no. 3, pp. 176-181, 2013.

[170] M. Turiel, L. Tomasoni, S. Sitia et al., "Effects of long-term disease-modifying antirheumatic drugs on endothelial function in patients with early rheumatoid arthritis," Cardiovascular Therapeutics, vol. 28, no. 5, pp. e53-e64, 2010.

[171] F. R. Spinelli, A. Metere, C. Barbati et al., "Effect of therapeutic inhibition of TNF on circulating endothelial progenitor cells in patients with rheumatoid arthritis," Mediators of Inflammation, vol. 2013, Article ID 537539, 8 pages, 2013.

[172] W. C. Yong, A. Sanguankeo, and S. Upala, "Association between primary Sjögren's syndrome, cardiovascular and cerebrovascular disease: a systematic review and meta-analysis," Clinical and Experimental Rheumatology, vol. 36, no. 3, pp. 190-197, 2018.

[173] V. Valim, E. Gerdts, R. Jonsson et al., "Atherosclerosis in Sjögren's syndrome: evidence, possible mechanisms and 
knowledge gaps," Clinical and Experimental Rheumatology, vol. 34, no. 1, pp. 133-142, 2016.

[174] Z. Brkic and M. A. Versnel, "Type I IFN signature in primary Sjögren's syndrome patients," Expert Review of Clinical Immunology, vol. 10, no. 4, pp. 457-467, 2014.

[175] Z. Brkic, N. I. Maria, C. G. van Helden-Meeuwsen et al., "Prevalence of interferon type I signature in CD14 monocytes of patients with Sjogren's syndrome and association with disease activity and BAFF gene expression," Annals of the Rheumatic Diseases, vol. 72, no. 5, pp. 728-735, 2013.

[176] G. Pagano, G. Castello, and F. V. Pallardó, "Sjøgren's syndrome-associated oxidative stress and mitochondrial dysfunction: prospects for chemoprevention trials," Free Radical Research, vol. 47, no. 2, pp. 71-73, 2013.

[177] Z. Yang and X.-F. Ming, "Recent advances in understanding endothelial dysfunction in atherosclerosis," Clinical Medicine \& Research, vol. 4, no. 1, pp. 53-65, 2006. 